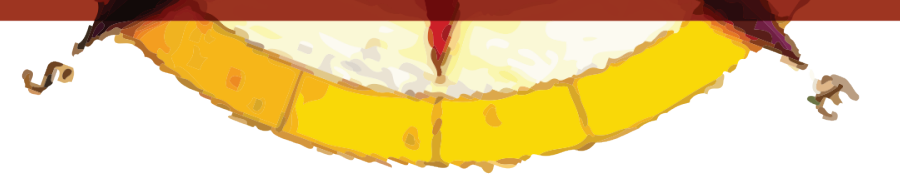

\title{
ESPACIALIDAD DE LO PÚBLICO EN LA CIUDAD CONTEMPORÁNEA: HORIZONTE DE ESTUDIO PARA LA GEOGRAFÍA
}

\author{
Felipe Castellanos Sepúlveda ${ }^{1}$
}

\section{RESUMEN}

Este artículo presenta algunas consideraciones conceptuales que pretenden proponer la espacialidad de lo público como un horizonte de estudio para la geografía, basándose en la fundamentación teórica realizada en un proceso de investigación sobre la construcción de significados de lugar público, en relación con la experiencia espacial y la vida cotidiana de personas en la Plaza de San Victorino de la ciudad de Bogotá. Esta reflexión pretende vincular lo público con lo espacial - la esfera pública con la espacialidad, lo público con la construcción de los lugares - con el fin de abordar problemas emergentes de la ciudad contemporánea en los que espacio público sea el centro de interés.

Palabras clave: espacialidad, significado de lugar público, espacio público, ciudad contemporánea.

\section{RESUMO}

Este artigo apresenta algumas considerações conceituais para propor a espacialidade do público como um horizonte de estudo para a geografia, com base na fundamentação teórica em um processo de investigação sobre a construção do sentido de os locais públicos, em relação à experiência espacial e vida diária de pessoas na Praça de San Victorino de Bogotá. Esta reflexão tem como objetivo vincular o público com o espaço - a esfera pública com a espacialidade, o público com os lugares - a fim de abordar os problemas emergentes da cidade contemporânea em que o espaço público é o foco.

Palavras Chave: espacialidade, o significado do lugar público, o espaço público, cidade contemporânea.

1 Profesor de la Licenciatura en Educación Básica con énfasis en Ciencias Sociales - Universidad Pedagógica Nacional. 


\begin{abstract}
This paper presents a conceptual considerations that intended to propose the spatiality of the public like a horizon of study for geography, based on the theoretical framework of a research process about the meaning of public place, related to the spatial experience and every life of people in the "Plaza de San Victorino" in Bogotá. This reflection related the public with the spatial - public sphere with spatiality, public with the construction of places - to study the emerging problems of the contemporary city where the public space is the protagonist.
\end{abstract}

Keywords: spatiality, meaning of public space, public space, contemporary city.

\title{
PRESENTACIÓN
}

Se presenta aquí un conjunto de relaciones conceptuales suscitadas durante un proceso de indagación ${ }^{2}$, que tuvo como problema central la construcción de significados de lugar público en personas vinculadas con el acontecer cotidiano de la Plaza de San Victorino de la ciudad de Bogotá.

Lo público, el espacio público, el lugar público y el significado de lugar público emergieron durante la investigación no sólo como categorías de análisis sino como conceptos que se proyectan al escenario de la teoría geográfica, considerando los fenómenos en los que se les puede rastrear, relacionados con la espacialidad o aún más directamente con el "tercer espacio" (Soja, 1997), el espacio de la vida cotidiana.

Esto puso a la investigación en un "campo ciego" que a decir de Henri Lefebvre enfrenta al conocimiento con la incertidumbre de lo desconocido y la certidumbre de la tradición. Si bien el espacio público y sus fenómenos tributarios han sido ampliamente estudiados desde distintas perspectivas epistemológicas y disciplinares, el panorama puede estar saturado de antecedentes o con partes ocultas: "por un lado se abre una vía a la exploración; por otro nos hallamos ante un muro que hay que romper, ante algo sagrado que hay que trasgredir" (Lefebvre, 1970: 38).

No se pretende proponer una interpretación inédita, pero sí una mirada a vínculos conceptuales que pueden interesar a la geografía y abordar las preguntas acerca de ¿qué es lo espacial en lo público? o ¿qué es lo público en lo espacial? Esto se traduce en una apuesta por relacionar nociones ampliamente exploradas en la geografía humana con nociones clave de la sociología o la antropología urbana para construir marcos de referencia útiles al proceso de observación del investigador.

\section{LA ESFERA DE LO PÚBLICO}

La palabra público no se puede desprender de su historia o por lo menos de su etimología. La cultura grecolatina ha transmitido a nuestro tiempo la denominación publicus que proviene de populos, que da origen a palabras como pueblo, población o público.

2 El trabajo titulado "Luchas diarias de compra y venta. Vida cotidiana y significados de lugar público en la Plaza de San Victorino” para optar al título de Magíster en Estudios Sociales de la Universidad Pedagógica Nacional. 
En la antigua Roma, la famosa sentencia "Vox populi, vox Dei" no aludía precisamente a la voz de todas las personas, considerando la fuerte jerarquía social encabezada por la aristocracia (aristos o los mejores) y por los ancianos (senatus). La misión de gobernar (gobernator o timonel) estaba concentrada en estas dos capas de la sociedad que conducían al pueblo o conjunto de ciudadanos (civis pertenecientes a la civitas o ciudad) y a la plebe (plebis o plural) que conforman el resto de personas que no participan en las decisiones de la ciudad (extranjeros, mujeres, esclavos y menores). El populus es el ciudadano joven, hombre, tal vez soldado o aprendiz, con voto pero sin derecho a gobernar. La voz del pueblo, que es voz de Dios, resultaba ser la voz de algunos que en el futuro tomarían el mando.

En la actualidad y después de la reinterpretación que la modernidad ha hecho de estos términos, se encuentran por doquier los discursos sobre el pueblo, la ciudad, la república, la democracia, el gobierno, el poder, la civilización, la ciudadanía, todos, sin excepción, relacionados con la forma de entender la vida social y, por otro lado, con lo público.

Para definir lo público es necesario reconocer que su raíz populos no se refiere a todos en la ciudad, distinto de lo que se tiende a concluir hoy: lo público como algo que "es de todos". Pero también hay que retomar lo socialis o societas, es decir, sociedad, la unión. Lo público se da gracias a la sociedad y en la medida en que ésta cambia, lo público se reacomoda a sus formas, manifestaciones o regularidades. En la idea de sociedad como unión está la centralidad de lo público: el encuentro de dos o más personas que son diferentes, que se unen con otros para un propósito.

No obstante, lo público no es sólo encuentro, en la medida en que publicus tiene una connotación de participación en la vida de la ciudad, de ejecución del papel de ciudadano que es civitas (haber echado raíces en la ciudad). Con Hannah Arendt (2005) puede discernirse mejor esta cuestión, abordando dos perspectivas para entender lo público.

En primer lugar, lo público depende de una condición plena de la publicidad o de la posibilidad de publicar (publicare o mostrarle al pueblo); es lo que siempre está visible ante los otros, considerando que "la presencia de otros, que ven lo que vemos y oyen lo que oímos nos asegura de la realidad del mundo y de nosotros mismos" (Arendt, 2005: 71). Es lo que persigue con la expresión "a la luz pública" y que Arendt presenta como la luz intensa de la esfera pública que ilumina lo socialmente apropiado y prescribe lo inapropiado a la esfera de lo privado, de lo íntimo.

En segundo lugar, lo público "significa el propio mundo, en cuanto es común a todos nosotros y diferenciado de nuestro lugar poseído privadamente en él [...] está relacionado con los objetos fabricados por las manos del hombre, así como con los asuntos de quienes habitan juntos en el mundo hecho por el hombre" (Arendt, 2005: 73).

Estas dos miradas permiten empezar a identificar vínculos interesantes acerca de la presencia de los otros, que en lo público asegura ser visibles (sacar a la luz), lo que también constituye la vida cotidiana como producción y reproducción acompañada del otro. Pero es más interesante aún la constatación de Arendt sobre los objetos fabricados y los asuntos en común, que como se entienden aquí, conforman dos grandes dimensiones del espacio público que garantizan el vínculo de los objetos y de las acciones como agentes modeladores de la esfera pública. 
Lo público es pensado aquí como esfera, como ámbito de realización de la vida social y de la vida cotidiana. Parafraseando una metáfora que propone Hannah Arendt, la esfera pública es como sentarse a la mesa con otros: la mesa reúne a los comensales, los enfrenta cara a cara pero no los relaciona directamente, los une y los separa al mismo tiempo, hace visible sus rostros y muestra una apariencia de cada persona pero no deja todo al descubierto. El significado de la mesa y lo que está en ella, relacionando y distanciando, es el interés de esta reflexión.

\section{ESPACIO PÚBLICO: OBJETO Y ACCIÓN}

Este proceso de indagación no se concentra directamente en el espacio público sino en la experiencia de las personas en su tránsito a ser lugar público, no obstante, se ve la necesidad de vincular esta noción con el concepto de espacio.

Como lo identificaba Arendt, lo público está relacionado con los objetos fabricados por el hombre, al respecto puede acudirse a la elaboración de Milton Santos que resalta la importancia de los objetos como un punto crucial en la construcción epistemológica de una categoría de pensamiento (el espacio), éstos se proponen como testimonio actual de la acción, por el cual es posible ver el acumulado de elementos y funciones que las sociedades humanas han dado a la vida material; en los objetos no sólo se encuentra su utilidad sino su inserción en un sistema coordinado de más objetos, es decir, a un sistema técnico que modifica, modela y altera el medio (Santos, 2000).

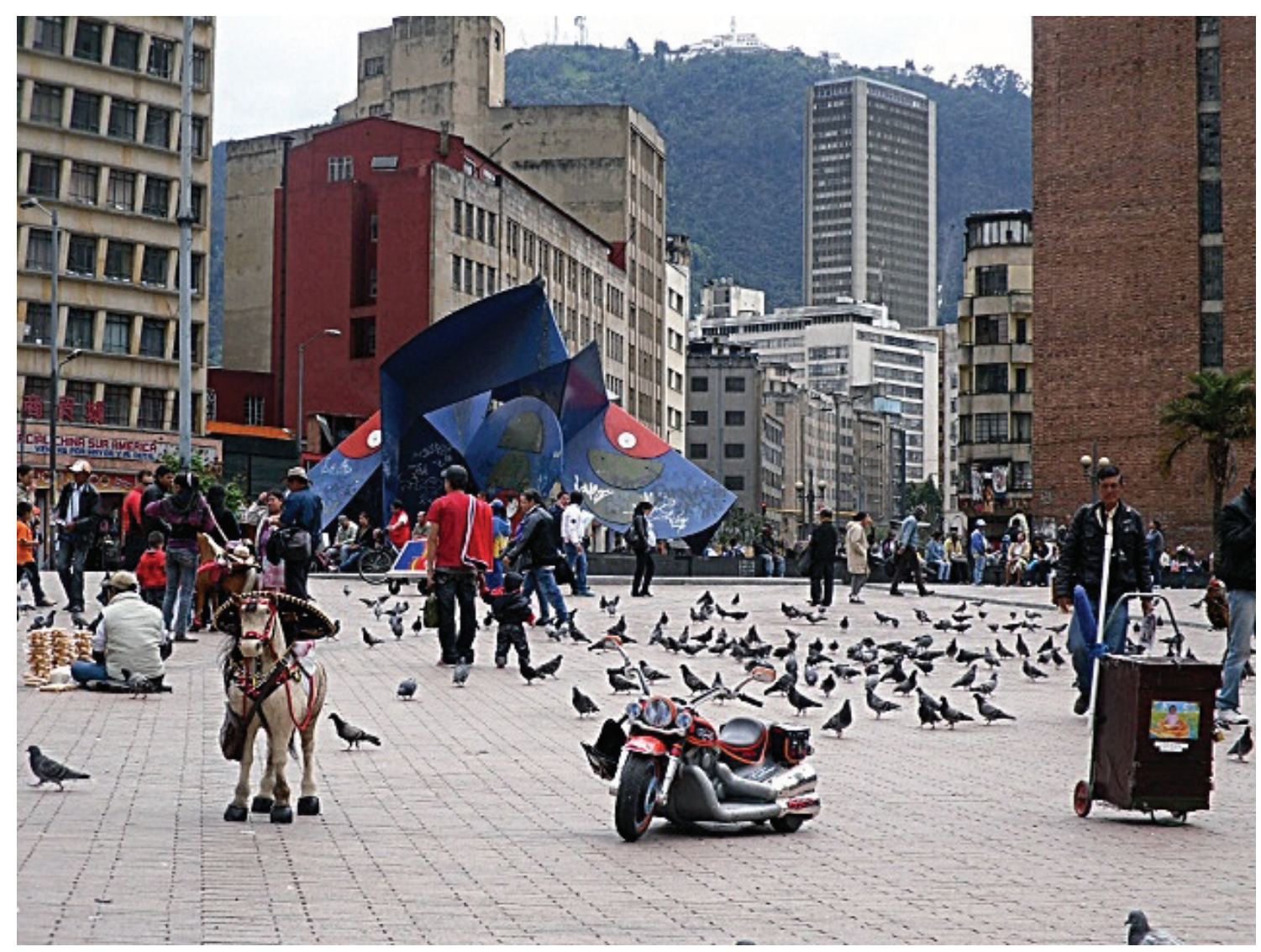

Foto 1: Vista panorámica, costado oriental de la Plaza de San Victorino.

Fuente: Archivo personal. 
Estos objetos les subyacen acciones y sistemas de acciones que los producen y los incorporan en la vida social, son actos proyectados hacia la realización de propósitos, son acciones intencionadas.

En este sentido, el espacio público puede plantearse como objeto geográfico, considerando su potencialidad al momento de evaluar la trayectoria de la acción humana, es un dato social y geográfico que toma distintas apariencias y significados en el tiempo. Un objeto geográfico, como el espacio público, es producto de las formas sociales y condiciona acciones humanas, por tanto, la ciudad contemporánea necesita de marcos específicos de estudio de su espacio público porque ha sido construido por distintos momentos del sistema técnico vigente y está generando nuevos sistemas de acciones, es decir, se recrea constantemente.

Este sistema de acciones tiene que ver con el segundo elemento de lo público según Arendt: los asuntos de las personas que habitan juntas en el mundo. Para la autora estos tienen que ver con la labor, es decir, con la posibilidad de fabricar y construir un mundo habitado, lo cual no se hace aisladamente - individualmente - como un animal laborans sino en estrecha cooperación como animal socialis (Arendt, 2005); el primero se abstiene de accionar con otros, el segundo es consciente de esto. Arendt sostiene que no sólo lo social vincula al ser humano con los otros sino también lo político, el zoon politikon griego, que tiene que ver con la relación social convertida en discurso para participar de la vida de la polis.

Así pues, los asuntos en común de lo público están entre la condición social y política del ser humano y además se dan en la ciudad, en un espacio que emerge en la historia como espacio público por excelencia donde, según Arendt, el fundamento de lo público depende de "la simultánea presencia de innumerables perspectivas y aspectos en los que se presenta en el mundo común", pero también del reconocimiento de que "quienes están presentes ocupan diferentes posiciones en él, el puesto de uno puede no coincidir más con el de otro que la posición de dos objetos [...] todos ven y oyen desde una posición diferente" (Arendt, 2005: 77).

Entendido así, el espacio público es el escenario de lo social y también de lo político en su modalidad de contradicción y conflicto de perspectivas, lo que no lo aleja de ser un lugar común, de encuentro, en donde las personas recrean la vida de la ciudad. El espacio público en la relación de objetos técnicos y acciones proyectadas, tiene la particularidad de congregar y disgregar simultáneamente, es un intercambio que puede ser violento o pacífico.

Este intercambio en la ciudad implica un encuentro con otros, con la alteridad. Es así como el espacio público es escenario de tensiones y conflictos producto del encuentro de visiones y actividades diferentes. Para Carrión, esa conflictividad que es connatural al espacio público, varía según el proceso histórico que se aborde y la ciudad donde se enmarque (Carrión, 2007), sobre todo porque el espacio público no se abstrae de la ciudad sino que es parte de ella y la convierte en una red de lugares, sustentada en la necesidad humana de intercambiar (cosas, mensajes, información, conocimiento, símbolos, etc.) para convivir pacíficamente.

Puede perfilarse el concepto de espacio público como "producto del uso social" (Borja, 2003: 179) que se construye por la fabricación de equipamientos u obras públicas y, a la par, por la creación de lugares significantes desde y para los ciudadanos. 


\section{USO Y APROPIACIÓN DEL ESPACIO PÚBLICO.}

A continuación se propone una complementación del concepto por medio de las categorías de uso y apropiación que serán de especial interés en la observación del investigador. Las dos se conciben como nodos de interacción entre los objetos fabricados y los asuntos en común que alberga el espacio público.

El uso hace referencia a la correspondencia entre actos y reglas, entre actos y normas. Todos los objetos según su forma y su función pueden ser utilizados para unos propósitos y para otros no, en la medida en que las acciones humanas dotan de sentido a los objetos, éstos van adquiriendo reglas y normas asociadas. Así también, el espacio público presenta en sus distintos momentos un conjunto de normas (acciones esperadas) y reglas (acciones prefiguradas y tipificadas) que son asimiladas en niveles de aceptación o rechazo. Páramo (2007) sostiene que el carácter público de los espacios no los exime de albergar un patrón de uso que remite a conductas específicas que se corresponden a reglas construidas a través del tiempo por los mismos ciudadanos, o reglas consignadas como leyes que rigen la relación de las personas con la institucionalidad.

Este uso del espacio público que está dado por la relación con las reglas se aprecia desde esta perspectiva como la relación entre formalidad e informalidad. Estas se plantean como las dinámicas de uso del espacio resultante de la tensión entre reglas y actos, entre reglas y prácticas cotidianas, entre reglas y acciones. Interesa más la relación de lo formal o lo informal como juego de intencionalidades alrededor del espacio público, más que como calificativo de personas o actividades laborales.

El uso que las personas hagan del espacio público, en la tensión entre formalidad e informalidad, define en gran medida lo público y sus expresiones en cada lugar de la ciudad, considerando la relación que las personas establecen con el espacio como "usuarios sin derechos de propiedad ni de exclusividad sobre ese marco que usan y se ven obligados a compartir en todo momento" (Delgado, 1999: 33).

Mientras tanto, vinculado estrechamente al uso, está la apropiación que se asume simultánea a la definición de patrones de uso en el espacio público, esta puede entenderse como parte integral de un "proceso que conduce a que la persona se apegue o se identifique con un lugar y busque adquirir control sobre éste" (Páramo, 2007: 79). Es crucial aquí el tránsito que hace el sujeto en proceso de apropiación hacia la significación del espacio.

No se abordan nociones tan importantes como la territorialidad o el hacinamiento, pero sí se apuesta por una observación de la apropiación del espacio como puerta de entrada a los significados que construye la persona, antes que a los objetos, en el proceso de incorporar el espacio a la experiencia, aclarando que "no son las cosas, sino los modos de relacionarnos con ellas de lo que nos apropiamos. $\mathrm{O}$ en otros términos, es del significado y las reglas del lugar de lo que realmente venimos a apropiarnos con el propósito de aumentar nuestro control sobre el ambiente" (Páramo, 2007: 82).

\section{LUGAR PÚBLICO}

No puede hablarse de espacio público y lugar público indistintamente. El primero es un campo de conocimiento y objeto de estudio que tiene múltiples implicaciones filosóficas, políticas, socioló- 
gicas y antropológicas, mientras que el segundo es un concepto geográfico o por lo menos alude a lo geográfico. Se toma entonces una distancia prudente de las elaboraciones que hablan de espacios públicos como sinónimo directo de lugares públicos o viceversa, lo que se atribuye a la dinámica de campos ciegos que se mencionó anteriormente.

No puede decirse tampoco que el espacio público deviene en lugares públicos o se compone de una variedad de lugares públicos. Puede existir la idea de espacio público sin que se den las condiciones necesarias para la construcción de lugares públicos. Pero, ¿cuáles son esas condiciones que permiten la existencia del lugar público? A continuación se proponen tres aproximaciones al respecto.

\section{El lugar público es espacio geográfico.}

El lugar se propone aquí como el cruce entre el situ, el locus y el topos, es decir, entre el espacio absoluto, relativo y el espacio vivido o, si se quiere, entre el espacio percibido, concebido y vivido. No obstante, el topos (la experiencia, la vivencia, la escala personal) es el elemento que le otorga su escala geográfica, su ámbito de relación frente a la conjunción de sistemas de objetos y sistemas de acciones, lo que a su vez es componente dinamizador de lo público.

En un lugar público pueden encontrarse datos geográficos que evidencian la trayectoria de la acción humana sobre el espacio, lo que se expresa en objetos fabricados y en decisiones conjuntas que las personas ponen a circular en el desarrollo de su vida pública, de lo visible ante otros. Una mirada centrada en los lugares públicos está enfrentada a la posibilidad de rastrear las visiones sobre el espacio desde la vida social en perspectiva histórica.

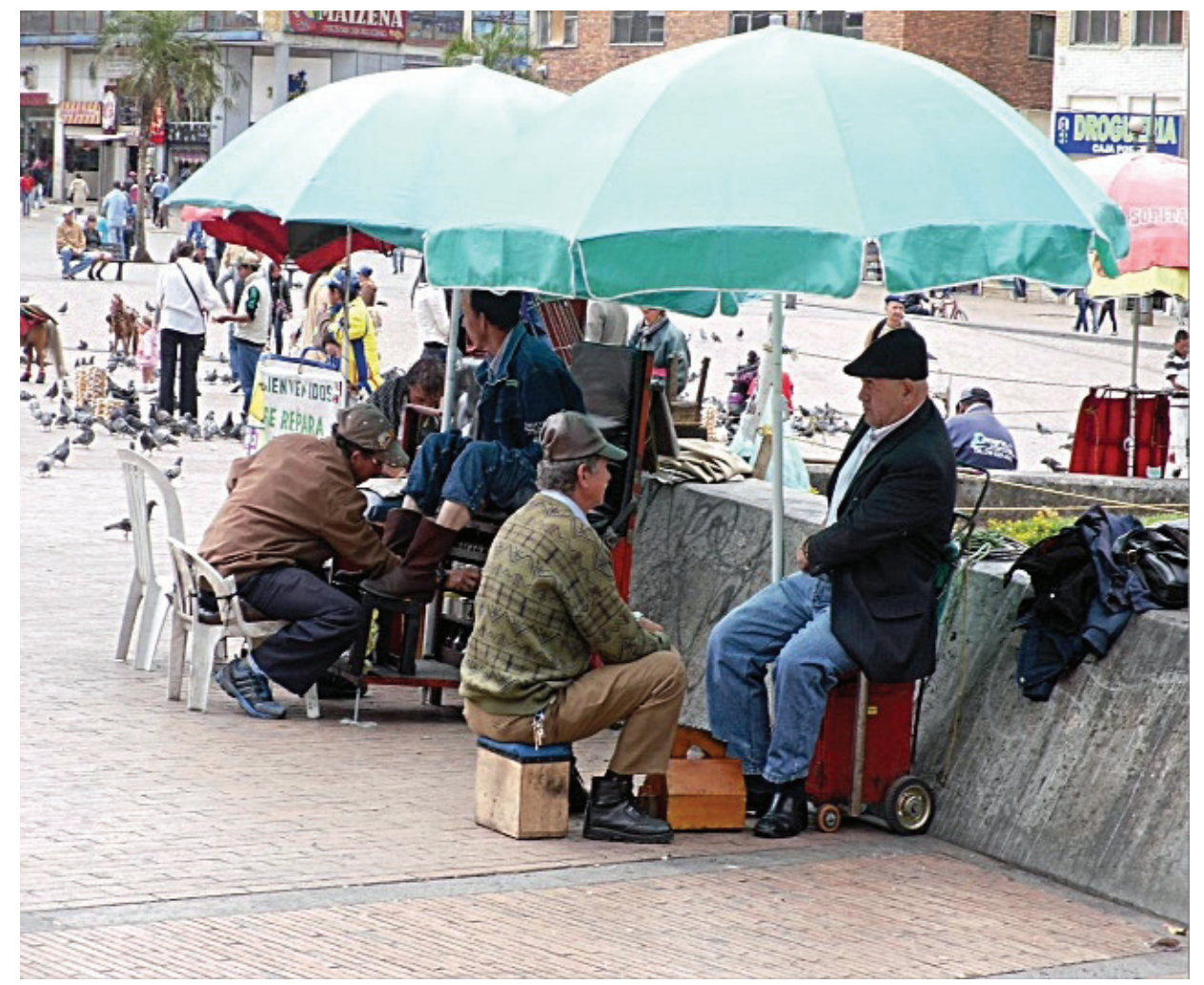

Foto 2: Los emboladores, costado occidental de la Plaza de San Victorino, Fuente: Archivo personal. 
Por otro lado, los lugares públicos no son posibles sin la existencia de un objeto geográfico de amplia relevancia para la historia de la humanidad: la ciudad. Esta forma de habitar el mundo y de modificar el espacio ha configurado en el tiempo circunstancias específicas para que los lugares públicos se construyan: la aglomeración, la vecindad, la densidad, la centralidad, entre otras.

\section{El lugar público es experiencia.}

El lugar es el resultado del movimiento la experiencia espacial de las personas, la cual se compone de sentimientos y pensamientos acumulados en el ejercicio de conocer el mundo. Esta experiencia espacial se construye de una manera idiosincrática en relación con sí mismo y con los otros, es decir, en desarrollo de una esfera privada en donde las acciones sólo importan y tienen sentido para la persona (intimidad, privacidad, lo que no aparece) y de una esfera pública que implica visibilidad y encuentro con los otros (Arendt, 2005).

Como lo señala Páramo, "los lugares desempeñan un rol significativo en las formas en que se organiza la vida cotidiana" (Páramo, 2207: 74), por esto es común ver una especialización de lugares según sea la esfera que privilegie (pública o privada), la escala de interacción (barrio, sector, localidad, etc.), los desplazamientos (lugar de residencia a lugar de trabajo), las actividades derivadas del oficio, profesión o empleo y los contactos con círculos de relación social como la familia, los amigos o los grupos de interés.

\section{El lugar público es urbano.}

Puede parecer una obviedad pero vale la pena aclarar este punto considerando que la revolución urbana que propone Lefebvre (1970) está basada en gran medida en el auge y cualificación del espacio público de las ciudades, por tanto, en la generalización de los espacios construidos para el encuentro de los ciudadanos se han intensificado las dinámicas de simultaneidad de experiencias; la movilidad y la inestabilidad de los vínculos ya no son la excepción sino la regla, se han convertido en el sentido mismo de lo público y de la posibilidad de intercambiar con los otros. El lugar público es eminentemente urbano porque reproduce la volatilidad de la vida urbana que pretende ser, a veces, detenida por la construcción de espacios públicos planeados y altamente especializados.

Lo anterior configura un objeto de conocimiento de carácter impredecible e indeterminado que se distancia del lugar propiamente dicho. El lugar o los lugares pueden encontrarse fácilmente porque dependen de la existencia del sujeto que los construye, mientras que el lugar público además de necesitar de una voz que lo presente como resultado de la experiencia espacial, depende del concierto de voces, intenciones y objetos contradictorios, es decir, demanda al investigador capacidad de síntesis. Así pues, una esquina cualquiera de la ciudad puede explorarse como lugar a partir de las experiencias de las personas que pasan o permanecen allí, pero al ser un fragmento del espacio público de la ciudad se convierte en un escenario donde esas mismas experiencias "salen a la luz", pasan a ser parte de la esfera pública como asunto que le importa a la ciudad.

El lugar público pone una inmensa columna de luz sobre las personas que participan de su construcción, lo que puede hacer que esos lugares permanezcan y tiendan a ser más acordes con las expectativas de la gente o, por otro lado, ser objeto de intervención radical desde actores que pretendan regular la esfera de lo público en la ciudad. La permanencia no es una cualidad central de los lugares 
públicos, por lo contrario, su condición es efímera, acompañada de lo invisible de sus componentes y de lo intangible de su conformación.

Una metáfora que podría perfilar el concepto de lugar público es la de una estela (rastro o huella que deja algo que pasa) que deja algo o alguien que está pasando y no deja de percibirse. El lugar público es algo que está pasando pero no deja de estar completamente y allí, en ese rastro, es donde debe mirarse fijamente para encontrar sus significados y sentidos. Se propone al lugar público como el rastro de la experiencia espacial de las personas en desarrollo de su vida pública en la ciudad, que está dada por la convivencia de prácticas cotidianas, roles sociales y escenarios cotidianos, modificado por la superposición de significados y sentidos que su permanencia y cambio le puedan otorgar.

\section{SIGNIFICADO Y SENTIDO DE LUGAR.}

En primer, hay que partir de la base de un campo en construcción que "implica el reconocimiento de que los lugares no sólo tienen una realidad material, sino que son construidos socioculturalmente a través de procesos sociales que los cargan con sentidos, significados y memoria, en la vida práctica" (Lindón, 2006: 379). Precisamente la vida práctica, lo cotidiano, es lo que circula incesante en la consideración de un lugar construido desde la subjetividad espacial y la experiencia espacial.

Se abre un horizonte de estudio que debe comenzar por definir, por ejemplo, la distancia y la cercanía entre el sentido de lugar y el significado de lugar. Aquí se opta por hacer una distinción en función de la perspectiva geográfica que se quiere enriquecer.

En primer lugar está el sentido o el sense que en la literatura geográfica escrita en inglés está bien distanciado del meaning (Tuan, 1977; Relph, 1976; Gustafson, 2001), lo que no es tan evidente en los estudios en español (Páramo, 2007; Lindón, 2000). Los segundos suelen pasar rápidamente de la noción de sentido a significado, convirtiéndola en sinónimo o componente una de la otra, mientras los primeros asignan al sense una connotación psicológica y cognitiva, y el meaning se relaciona con lo semántico y el lenguaje.

El sentido aquí se relaciona con la percepción y con la conciencia. Por un lado, el sentido como percepción invita, como lo hace Tuan (1977), a transitar entre la respuesta sensorial, biológica, de las personas y la construcción subjetiva - en relación con la cultura y la organización social - que se hace de los lugares. Llegar a dar sentido por medio de la percepción es entonces una experiencia sensorial que está orientada por los aprendizajes de la cultura, así pues, el sentido de las cosas y del mundo cambia y se hace singular en cada grupo social.

El sentido como conciencia se constituye "en la conciencia del individuo, que está individuado en un cuerpo y ha sido socializado como persona" (Berger, 1997: 3), es decir, es un proceso tanto individual como colectivo, modelado por el contacto con lo íntimo y los otros cercanos. Sin embargo, la conciencia no se hace por sí misma sino que siempre es conciencia de algo, orientada a un propósito, por tanto, el sentido está definido por la elección del individuo socializado, "no es más que una forma algo más compleja de conciencia: no existe en forma independiente. Tiene siempre un punto de referencia. El sentido es conciencia del hecho de que existe una relación entre las varias experiencias" (Berger, 1997: 3). 
Tenemos entonces al sentido como experiencia subjetiva de carácter singular que se tiene del mundo en presencia de la multiplicidad de experiencias en la vida social, cultural o cotidiana. Por otro lado, está el significado que se abordará desde algunos supuestos para luego llegar a su vinculación con las nociones de signo y lo imaginario.

Consultar a alguien sobre el significado que tiene sobre algo (objeto, hecho, acción, lugar, palabra, etc.) es un intento superficial e ingenuo, en la medida en que se lograrían respuestas inmediatas tendientes a lugares comunes, eslóganes o datos arbitrarios que no dan cuenta de la complejidad de la relación entre el sujeto y su mundo percibido, concebido y vivido.

A este supuesto se une un precedente pedagógico que incorpora la construcción de significados como fin mismo del aprendizaje (aprendizaje significativo de David Ausubel) y que propone, a grandes rasgos, una combinación significativa de momentos de aproximación al conocimiento en la que los conceptos (significados) no pueden construirse sin la participación de pre-conceptos y elementos potenciales que motiven la aparición de nuevos conceptos (nuevos significados).

La propuesta saussureana de la interacción entre signo, significado y significante que intenta comprender la producción lingüística a partir de una unidad en donde el significado remplaza al concepto y el significante a la imagen acústica (Sánchez, 1999), provee elementos básicos en el plano del desenvolvimiento del lenguaje, mas no en el plano de lo antropológico que va más allá de las nomenclaturas y toca la experiencia histórica y espacial del ser humano.

Por esta vía, puede plantearse que los fenómenos que rodean la construcción de significados no obedecen exclusivamente a la movilidad en el universo de lo sensible o a la conversión empírica de los significados (conceptos, ideas, nociones, etc.) en significantes (objetos, cosas, artefactos, etc.). Se evidencia entonces la imposibilidad ontológica de reducir la comprensión de fenómenos a su expresión material o inmaterial, dado que la experiencia humana se compone de hibridaciones que permiten ligar lo imaginario con lo real, tal como lo proponen los lenguajes artísticos de la literatura, las artes plásticas, el cine o la música.

Acudiendo a Gilbert Durand y la distinción entre las formas directas e indirectas de representar el mundo, puede decirse que la construcción de significados no se ubica tajantemente en un lado o en otro, sobre todo porque las presencias (sensibles, directas) y las ausencias (imaginarias, indirectas) no están al margen de la posibilidad de representar el mundo, aun cuando haya significados de difícil expresión (Durand, 2000).

Pero, ¿qué hacer ante una parte del mundo que su razón de ser es la sinergia entre presencias y ausencias? Es el caso del lugar, que como se ha dicho, es resultado de la experiencia espacial y se debate entre el situ (percibido), el locus (concebido) y el topos (vivido). Se introducen las tipologías de signos, signos arbitrarios y alegóricos, para abordar esta cuestión.

El situ estaría caracterizado por los signos arbitrarios que Durand denomina como indicativos (señalan algo y su función), mientras el locus y el topos estarían plagados de signos alegóricos. Es así como una plaza pública se caracteriza como signo indicativo gracias al espacio libre y abierto que ofrece a su visitantes, pero también por la importancia que le dan el conjunto de acciones y de objetos que le son propios, lo que trasciende al escenario de lo histórico, lo patrimonial, lo vivencial y lo social. 
El signo alegórico es el caso de "La Mariposa" de la Plaza de San Victorino creada por Edgar Negret, instalada allí con un propósito estético de integración de los ciudadanos con el espacio público de la ciudad y que con el tiempo ha pasado a relacionarse con actividades como la prostitución infantil o el microtráfico de drogas. El signo alegórico no sólo refiere a un sitio dentro de la ciudad sino a un conjunto de actividades - socialmente aprobadas o no - que la experiencia humana permite desplegar, va más allá de lo que el significante (imagen acústica) puede generar, está en el mismo origen de los significados y de los imaginarios, permitiendo la conexión de un signo con la historia, la memoria y la tradición.

En este sentido, el lugar puede asumirse como "realidad significada difícil de representar" (Durand, 2000: 12) y se acerca en el plano de la reflexión a lo imaginario, en la medida en que la unión entre significados y significantes deviene en signos, a veces, en signos tales como el símbolo, es decir, un componente constitutivo de lo imaginario. Aunque lo que Durand (2000) 1lama imaginación simbólica no es el interés central de la investigación, es necesario aclarar que en la observación del lugar emerge la posibilidad de presentar los significados teniendo como certeza que los signos (indicativos y alegóricos) refieren a múltiples sentidos (intangibles) y a cosas sensibles.

Si bien la búsqueda de significados de un lugar va más allá de lo sensible no se puede decir que se convierte en algo "ausente o imposible de percibir" (Durand, 2000: 13). Seguramente pueda decirse que existen lugares simbólicos, dotados de signos que presentan un conjunto de atributos imperceptibles, no obstante, esos lugares se guardan en las personas, gracias a elementos de la percepción y la experiencia desarrollada allí. Un ejemplo de esto son los lugares donde se registran apariciones divinas. El lugar no es lo simbólico en sí mismo, pero sí lo es la sustancia de la aparición, el significado de lo que aparece y que no puede explicarse, las bondades del ser divino que aparece en una casa, montaña o camino, seres divinos que, por cierto, no son asibles sino en la representación que las personas hacen de ellos.

Investigar los significados implica investigar sobre lo imaginario debido a que la unión entre signos y significados constituye lo simbólico, que es a su vez parte del imaginario cultural definido por Sánchez (1999) como "el saber cultural de la especie" que es continente (deposito del conjunto de la experiencia de la humanidad) y contenido (modo de ser y situarse frente al mundo). Los significados entrarían en este escenario como reductos de experiencias individuales y colectivas, diferenciables en el tiempo y el espacio que permiten aseverar la existencia de unidades particulares dentro del proceso de devenir histórico y social.

De allí que las culturas tengan distancias irreconciliables en sus significados acerca del tiempo, el espacio, la verdad, el conocimiento, el saber, la justicia o el poder, mientras se den insólitas coincidencias entre las cosmovisiones, lo que obedece desde luego al repertorio de significantes que se construyen en cada sociedad, a las formas diversas de representar lo que no es tangible y, en suma, a la construcción idiosincrática de imágenes o esquemas de comprensión sobre lo que no se conoce y puede conocerse.

\section{SIGNIFICADO DE LUGAR PÚBLICO.}

Basado en la existencia del sentido que se realiza en la percepción y en la conciencia, además del significado que depende de la observación de los signos y lo imaginario, esta indagación se concentra en la noción de significado del lugar porque recoge los dos énfasis de la distinción conceptual 


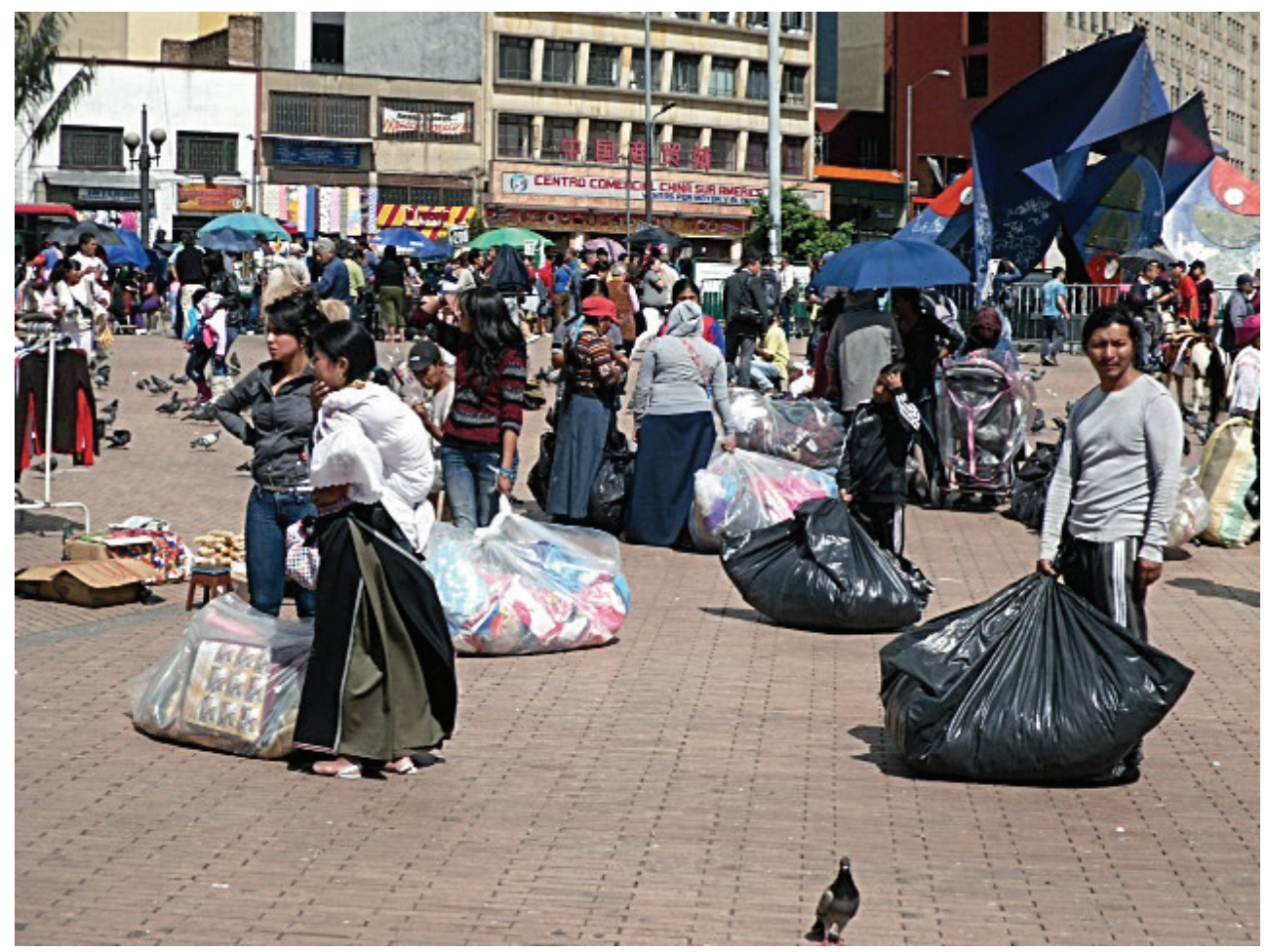

Foto 3: Los Otavaleños, costado sur de la Plaza de San Victorino. Fuente: Archivo personal.

entre sentido y significado. Es evidente que para llegar al significado que las personas tienen de un lugar es necesario fijarse en lo sensorial y en lo hecho conciencia; pero el vínculo de estos dos ámbitos con lo público pasa por la consideración de al menos tres relaciones que se establecen con el self, los otros y el ambiente.

En primer lugar está la relación self, o la relación consigo mismo, con el yo. Todos las personas desarrollan su experiencia vital en lugares reconocibles y diferenciables, lo que corresponde al emplazamiento del núcleo familiar o los azares de la ubicación de las personas con respecto a su actividad, no obstante, por más amplio que sea el desplazamiento de un persona en el espacio, siempre va a existir un lugar de nacimiento. Aunque cada vez son menos importantes las procedencias de las personas en un mundo globalizado, es común que los Estados definan quién es o quién no es ciudadano; puede que la persona sea ciudadana de determinado país pero haya nacido en otro, o viva en país teniendo otra nacionalidad y habiendo nacido en otro lugar.

No obstante estas configuraciones, la persona tiende a sentirse vinculada a unos lugares más que a otros, lo que se define por su residencia permanente o semipermanente y por las relaciones de uso, indagación o vivencia que Tuan presenta (1983). La experiencia se realiza en lugares y construye esos lugares. Un adulto mayor habitante de una ciudad por muchos años, con estancias muy cortas en otras ciudades, puede dar testimonio de su vínculo con esa ciudad, al igual que el joven que decide quedarse en esa misma ciudad durante un par de años para estudiar, trabajar o preparar su viaje a otros sitios. En los dos casos podrá observarse que la ciudad de residencia, sus hogares, los lugares donde compran alimentos o donde van a dar un paseo les generan algún tipo de emociones y recuerdos (Páramo, 2007). 
Por otro lado, estas personas, habitantes permanentes o esporádicos, foráneos o propios, entran en una relación con otras personas. El ámbito de la familia sigue siendo uno de los más cercanos, las personas tienen la tendencia a saber dónde viven sus familiares y en ocasiones a ubicar sus residencias cerca entre unos y otros, igualmente, las relaciones de amistad se hacen en el barrio, el lugar de trabajo o de estudio. La relación con otros en los lugares públicos aunque no deja de ser un intento de acercamiento, es sobre todo una ruptura de esas relaciones cercanas para darle paso a un anonimato fortuito que depende de la exposición pública: "una invisibilidad relativa, que consiste en ser visto y no visto, ser tenido en cuenta pero sin dejar de ocultar su verdadero rostro" (Delgado, 1999: 17).

La otredad que configura el significado del lugar público es una relación de distanciamiento pero a su vez de cercanía con "las características percibidas y los comportamientos de sus habitantes con los que el individuo se siente identificado" (Páramo, 2007: 73). Es por eso que es necesario explorar cómo se dan las relaciones de convivencia entre las personas que comparten tiempo, objetos y decisiones en los lugares públicos.

Por último, la relación con el ambiente que es entendido como entorno de realización de la vida pública provisto de atributos materiales e inmateriales con los cuales se establece una relación de uso y de valoración estética. Cada persona en relación con los otros puede usar el lugar para fines diversos como el trabajo, la recreación o el ocio, lo que prefigura una valoración acerca de la disposición de las cosas en el entorno. Si en el lugar público se vive una experiencia de carácter traumático como un robo, una catástrofe, una calamidad, etc., esto influye en las sensaciones o emociones que se puedan expresar a otras personas sobre ese lugar.

En la relación con el ambiente, al hablar de usos y valoraciones, es necesario ver la satisfacción de necesidades cotidianas como descansar, alimentarse, ir al baño, hacer una llamada, realizar trámites o cuidar los objetos personales, de esto dependen sensaciones de bienestar o desagrado con respecto al entorno.

Estos tres elementos, el self, la relación con los otros y con el ambiente configuran las fuentes básicas del significado de los lugares públicos como rastros del encuentro cotidiano entre personas diferentes. La intención es resaltar la posibilidad que se abre al conjugar conceptos como percepción, conciencia, signo e imaginario - que sirven de marco analítico para el investigador - con categorías aplicadas a la observación del contexto de estudio (self, otros y ambiente), ya que allí, en el intermedio se encuentra el debate por la publicidad del espacio y la espacialidad de lo público.

\section{ESPACIALIDAD DE LO PÚBLICO, HORIZONTE DE ESTUDIO.}

Ante la diversidad y complejidad del panorama de lectura teórica que se ha planteado aquí, se parte del siguiente enunciado para proponer algunos puntos de síntesis:

El espacio público es vivido como espaciamiento, esto es como «espacio social regido por la distancia». El espacio público es el más abstracto de los espacios - espacio de las virtualidades sin fin -, pero también es el más concreto, aquel en el que se despliegan las estrategias inmediatas de reconocimiento y localización [...] es un espacio diferenciado, esto es territorializado, pero las técnicas prácticas y simbólicas que lo organizan espacial o temporalmente, que lo nombran, que lo recuerdan, 
que lo someten a oposiciones, yuxtaposiciones y complementariedades, que lo gradúan, que lo jerarquiza, etc., son poco menos que innumerables, proliferan hasta el infinito, son infinitesimales, y se renuevan a cada instante. No tienen tiempo para cristalizar, ni para ajustar configuración espacial alguna (Delgado, 1999: 34).

Recuérdese a Hannah Arendt en su metáfora de la mesa puesta para los comensales para explicar la esfera pública, evidentemente, la distancia es necesaria, no para ampliarla, sino para generar situaciones de acercamiento; la distancia está dada por algo en común que se proyecta por la presencia de las personas: el espacio público. Y si las ausencias, la virtualidad, se convierten en lo que mueve la situación y sus elementos, es entonces una condición inexcusable de ese tipo de experiencia espacial, de esa espacialidad de lo público.

El horizonte de estudio que se presenta aquí no es la certeza de unas relaciones encontradas y validadas por la elaboración conceptual, considerando que el recorrido que se ha hecho deja más preguntas e incertidumbres que respuestas concretas. No obstante, este es en parte la misión de todo estudio que se enfrenta a campos emergentes en el ámbito disciplinar y a campos ciegos en el campo epistemológico.

Se toma al espacio público en su potencialidad conceptual y en su palpitación como fenómeno urbano contemporáneo que puede ser analizado desde el juego de objetos y acciones, es decir, desde su geograficidad, pero también desde su papel viabilizador de experiencias espaciales que sólo emana de la relación entre la vida cotidiana, la vida pública y la vida urbana.

La espacialidad de lo público es, en primera instancia, una apuesta por la vida cotidiana como puente de sentido. Aquí las prácticas cotidianas, los roles, las rutinas y los escenarios que se construyen en el diario vivir de las personas conectan lo espacial con lo público, si se entiende a lo cotidiano como momento de la acción, esa interfaz entre lo que se hace siempre y lo que puede hacerse, lo cual obedece al movimiento acompasado de actuantes en pleno uso de sus roles.

La espacialidad de lo público plantea la observación sobre el rastro que deja la vida en público de las sociedades. Ese rastro puede ser perenne o fugaz y son los lugares públicos los que lo albergan. Si la vida pública garantiza visibilidad, pero al tiempo exige de una cuota alta de anonimato, los lugares producto del cruce de experiencias espaciales en la ciudad son tremendamente inestables e inciertos, no sólo porque se modelan por el paso efímero de las personas y por sus diferentes personalidades, sino porque sus significados no logran afianzarse en el imaginario y la memoria de la ciudad. Este campo de estudio es necesario porque puede construir una geografía de la vida pública en las ciudades, empezando por el rescate de los significados que las personas otorgan al espacio público.

La espacialidad de lo público es otro punto de anclaje para el estudio de la vida urbana y, en la actualidad, de los fenómenos inéditos de urbanización sin ciudad o construcción de ciudad sin urbanización. Aquí se hace más patente la preocupación por una ciudad que no promueve la vida pública ya que no se hace así misma significante para sus habitantes: "la ciudad sin estética no ética [...] el plus es el sentido, el simbolismo, el placer, la emoción [...] La responsabilidad principal del urbanismo es producir espacio público, espacio funcional polivalente, que relacione todo con todo" (Borja, 2003: 28-29). 
Lo urbano pasa por la consideración de la trayectoria y momento presente del espacio público, y como tal, de la construcción paulatina, a veces oculta e invisible, de los lugares públicos que hierven en los centros urbanos, en las periferias, en los espacios que apropian algunos y otros no, en la instauración de prácticas que subvierten las normas y las reglas urbanas.

Lo espacial en lo público es la coexistencia de acciones y objetos movidos por la energía de la experiencia y la vida cotidiana, del lugar y lo cotidiano. Lo público en lo espacial es el transito incesante de la alteridad humana, de sus asuntos y obras comunes, por la red de lugares que conforma el espacio.

\section{REFERENCIAS}

Arendt, H. (2005). La condición humana. Barcelona: Paidós.

Berger, P. y Luckman, T. (1997). Modernidad, pluralismo y crisis de sentido. Barcelona: Paidós.

Borja, J. (2003). La ciudad conquistada. Madrid: Alianza Editorial.

Carrión, F. (2007). Espacio público: punto de partida para la alteridad. En Segovia, O. (Ed.) Espacios públicos y construcción social. Hacia un ejercicio de ciudadanía. Ecuador: Facultad Latinoamericana de Ciencias Sociales, FLACSO.

Curry, M. (2002). Everyday practices and public places. University of California. Los Ángeles.

Delgado, M. (1999). El animal público: hacia una antropología de los espacios urbanos. Barcelona: Anagrama.

Durand, G. (2000). La imaginación simbólica. Buenos Aires: Amorrortu editores.

Foucault, M. (1967). De los espacios otros. Architecture, Mouvement, Continuité, N 5, octubre de 1984. París.

Goffman, E. (2009). La presentación de la persona en la vida cotidiana. Buenos Aires: Amorrortu.

Gustafson, P. (2001). Meanings of place: everyday experience and theoretical conceptualizations. Journal of Environmental 21, pp. 5-16, Universidad de Göteborg, Suecia.

Hiernaux, N. (2006). Repensar la ciudad: la dimensión ontológica de lo urbano. Liminar. Estudios Sociales y Humanísticos, Año/vol. IV, No. 002, pp. 7-17. Universidad de Ciencias y Artes de Chiapas, San Cristóbal de las Casas. México.

Lefebvre, H. (1970). La revolución urbana. Madrid: Alianza Editorial.

Lindón, A. (2000). Del campo de la vida cotidiana y su espacio-temporalidad (una presentación). En Lindón, Alicia (Comp.). La vida cotidiana y su espacio-temporalidad. Barcelona: Anthropos. 
Lindón, A. (2006). Geografías de la vida cotidiana. En Daniel Hiernaux-Nicolás (coord.). Tratado de geografía humana. Anthropos. México: Universidad Autónoma Metropolitana. Unidad Iztapalapa.

Páramo, P. (2007). El significado de los lugares públicos para la gente de Bogotá. Universidad Pedagógica Nacional. Bogotá.

Relph, E. (1976). Place and placelessness. Pión: Londres.

Sánchez, C. (1999). Imaginación y sociedad: una hermenéutica creativa de la cultura. Madrid: Tecnos - Universidad Pública de Navarra.

Soja, Edward (1997). El tercer espacio. Ampliando el horizonte de la imaginación geográfica. Geographikós, N 8. Buenos Aires.

Tuan, Y. (2001). Space and place. The Perspective of Experience. Minneapolis: University of Minnesota Press.

Tuan, Y. (2007) Topofilia: un estudio de las percepciones, actitudes y valores sobre el entorno. Barcelona: Editorial Melusina. 